\title{
Impact of country of birth on hospital admission for women of childbearing age in Sweden: a five year follow up study
}

\author{
E Robertson, M Malmström, J Sundquist, S-E Johansson
}

J Epidemiol Community Health 2003;57:877-882

See end of article for authors' affiliations

\section{Correspondence to:} Eva Robertson, Family Medicine Stockholm, Alfred Nobels allé 12, SE-141 83 Huddinge, Sweden; eva.robertson@ klinvet.ki.se

Accepted for publication 22 April 2003
Study objective: This study examines whether morbidity, defined as the first psychiatric hospital admission and the first somatic hospital admission, differs among subgroups of foreign born and second generation (that is, native born with at least one parent born abroad) women compared with Swedish born women (that is, with both parents native born) after adjusting for sociodemographic factors.

Design/Setting: In this follow up study the population consisted of 1452944 women, of whom 369771 have an immigrant background (including second generation immigrants), aged 20-45 years. The population of 31 December 1993 was followed up to 31 December 1998. Differences in risk (hazard ratio) between different groups of immigrant women were estimated, adjusting for age, marital status, number of children, and disposable income.

Main results: All four groups of foreign born women had higher age adjusted risks (HRs varied from 1.44 to 1.67$)$ for a first psychiatric hospital admission than Swedish born women. The risk decreased only marginally when the sociodemographic factors were taken into consideration. Additionally, second generation women also had a higher age adjusted risk $(\mathrm{HR}=1.42 ; \mathrm{Cl}=1.37$ to 1.48$)$ than Swedish born women. The risk decreased only slightly in the main effect model. However, on analysing country of birth and first somatic hospital admissions, only non-European refugee women showed an increased age adjusted risk ( $\mathrm{HR}=1.26 ; \mathrm{Cl}=1.24$ to 1.29$)$, which remained after adjusting for sociodemographic factors. Conclusions: Foreign born and second generation women of childbearing age had a higher risk than Swedish born women for a first psychiatric hospital admission. However, only non-European refugees were at higher risk of somatic hospital admissions.
E ven though the health of different ethnic groups has become an increasingly important topic worldwide, our knowledge of the health of immigrant women is limited. In recent years, studies have shown that foreign born women have different patterns of utilisation and access to health care services from native born women. ${ }^{1-4}$ Several studies have shown higher incidence rates of communicable diseases such as tuberculosis, ${ }^{5-7}$ STD, and $\mathrm{HIV}^{8}$ and poor reproductive health, such as low birth weight, increased perinatal, and postnatal mortality and morbidity ${ }^{10}$ among certain immigrant groups. Some studies show increased admission rates for immigrants, but mostly for inappropriate use of emergency services due to an inappropriate level of care and the quality of or access to care. ${ }^{11}{ }^{12}$ To our knowledge no other studies have been published concerning general somatic hospital admission among ethnic minorities. However, it has been recognised that, in terms of screening, treatment, and palliation of cancer, services are not always accessible and sensitive to the needs of minority ethnic people. ${ }^{13}$ Epidemiological studies in Britain, Denmark, Sweden, and the Netherlands have shown increased incidence rates of schizophrenia and schizophrenia-like psychoses in some ethnic minority groups. ${ }^{14-17}$ Other studies from Sweden have demonstrated that foreign born people have a high risk of attempted suicide, ${ }^{18}{ }^{19}$ suicide, $^{20}$ psychological distress, and psychosomatic complaints. ${ }^{21}$

In recent decades immigration to Sweden has changed from being dominated by actively recruited immigrants (between 1948 and 1967) to a strongly restricted policy whereby only persons with specific expertise and skills (mostly from western/westernised countries) have been welcomed. From the 1970s and 1980s, the non-European refugee migration increased considerably and, in the 1990s, also refugee migration from the Balkan countries. However, there is lack of representative and comparative Swedish data on the morbidity of different subgroups of immigrant women of childbearing age.

The second generation - that is, those born in Sweden with at least one foreign born parent, is a growing group of young women about whose health status little is known. A study from the UK shows that the patterns of limiting long term illness continued across generations among all groups, with low socioeconomic status (SES) accounting for most of the higher risks. ${ }^{22}$

It is a well known fact that increased morbidity and mortality have been found in women with low educational status, manual employment, and/or low income, compared with women with higher SES. ${ }^{23-25}$

In this study we explore whether foreign born and second generation women aged 20-45 at the start of the study have higher morbidity, defined as the first psychiatric hospital admission and the first somatic hospital admission during 1994-98, than Swedish born women and whether this morbidity remains after including sociodemographic factors.

\section{METHODS}

This follow up study includes all women aged 20-45 in Sweden 31 December 1993-that is, 1452944 women, 176863 of whom are second generation (that is, native born women with at least one parent foreign born) and 192908 foreign born women. The women were followed up until a first hospitalisation for somatic disease and a first hospitalisation for psychiatric disease or out-migration from Sweden, death or censure at the end of the study on 31 December 1998. To avoid a selection bias, women hospitalised three years prior to 1994 were excluded. We have also excluded pregnancy, birth, and postpartum related diagnoses as this study focuses on disease. Furthermore, injuries, drug 
and alcohol abuse diagnoses were excluded because of missing data and difficulties in classification.

The longitudinal database "MigMed" was used. It comprises linkages with several other databases: Louise, a total register of the Swedish population, including the entire population of 2 million women born before 1986, 0.5 million of whom have an immigrant background (including second generation immigrants), with information on SES and place of residence. The Immigration Register contains data on immigration, emigration year (time in Sweden) and country of birth. The Total Population Register (RTP) consists of all people who have a residence permit. It includes data on movements such as divorce, marriage, out-migration and return to Sweden. The Cause of Death Register comprises all causes of death during the year in question irrespective of whether the death occurred in Sweden or abroad for those who were registered in Sweden at the time of death. This register is based on WHO recommendations, ICD9 and ICD 10. The under-coverage and over-coverage is very low. The In-Care Register is based on WHO recommendations and contains hospital admissions (diagnoses and admission data and date of discharge) according to ICD9 and ICD10. Each person can be tracked from 1991 to 1998 .

\section{Outcome variables}

First psychiatric hospital admission for women aged 20-45 years at the start of the study.

First somatic hospital admission for women aged 20-45 years at the start of the study.

\section{Explanatory variables}

Age (at baseline) was categorised in the following five year groups: 20-24, 25-29, 30-34, 35-39, and 40-45 years.

Country of birth was categorised with references to Swedish women-that is, Swedish born women with both parents born in Sweden, and second generation women-that is, born in Sweden with at least one foreign born parent. Foreign born is used as a group category for all women born abroad. We divided the foreign born women into women from western/westernised countries (that is, USA, Canada, Australia, Japan, New Zealand, the Baltic states, and northern and central Europe) and women from Finland and southern Europe (the former Yugoslavia, Italy, Greece, Spain, and Portugal) as two groups of labour immigrants. The reason for the grouping is not to create new categories, although in earlier studies ${ }^{26} 27$ it has been shown that the health of women from southern Europe and Finland is similar and differs with respect to the other western/ westernised countries. The foreign born women who came as refugees were divided into European refugees-that is, women fleeing from war and political and religious oppression from countries in eastern Europe and the Balkan countries (in the 1990s), and non-European refugees, women from countries in Latin America, Asia, and Africa.

Marital status comprised two groups: married/cohabiting and single. However, cohabiting women without children are categorised as single because of the registration system in Sweden. ${ }^{28}$

Number of children was categorised into four groups: 0 child, 1 child, 2 children, and more than 2 children.

Disposable income was used to give a proportional estimate of the economic resources of the woman. It was categorised/ divided into quartiles, high (reference group), middle-high, middle-low, and low income, and was calculated from the sum of the whole family's income multiplied by an individual consumerweight for each person in the family divided by the family's total consumerweight and then multiplied by the basic yearly amount (geared to the price index, annually stipulated by the Swedish government) here used from 31 December 1993. ${ }^{29}$

\section{Statistical methods}

The data were analysed using a proportional hazard model, Cox regression ${ }^{30}$ by first psychiatric hospital admissions and first somatic hospital admissions to estimate the hazard ratio (HR) for the morbidity of women of childbearing age. The HR can be expressed as the ratio of the hazard functions between two groups and is calculated by exponentiation of the regression coefficient. The results are presented as HR with $95 \%$ confidence intervals (CI). The change in -2 log likelihood was used as a measure of improvement in model fit, when including a covariate. The proportional hazards assumption was analysed by inspecting $\log (-\log )$ survival curves for parallelism and by including the interaction between time and each of the independent variables.

Interactions between country of birth and disposable income are shown in an age adjusted model (fig 1). These interactions are not included in the main effect model.

\section{RESULTS}

The distribution of the independent sociodemographic variables in 1994-98 is presented in table 1. There were 1452944 women in the age range 20-45. The smallest immigrant group ( $1.1 \%$ of the total population in that age span) is the European refugees mainly coming from the Balkan states and the largest group (5.9\%) is the non-European refugees.

Labour immigrants from Finland and Southern Europe and non-European refugees had the highest incidence rate of first psychiatric hospital admissions (table 1). Single women had twice as high age adjusted incidence rate of first psychiatric hospital admissions as married/cohabiting women. Women with high income showed about 30\% lower incidence rate for first psychiatric hospital admissions than the other income groups, after adjusting for age.

In table 2, the estimated hazard ratios (HR) with 95\% confidence intervals (CI) for first psychiatric hospital admissions during 1994-98 are shown in two models: an age adjusted one and a main effect model. Women labour immigrants born in Finland and southern Europe and nonEuropean refugees had about $70 \%$ higher risks of a first

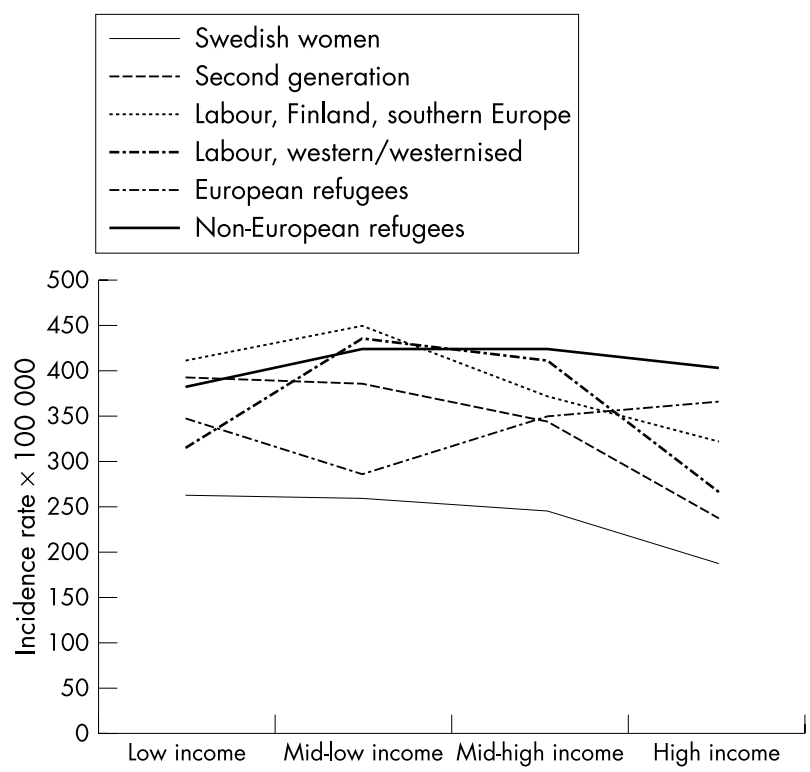

Figure 1 Interactions between country of birth and disposable income concerning first psychiatric hospital admission 1994-98, age adjusted incidence rate. 
Table 1 Distribution of the independent variables and admission rates for first psychiatric and somatic hospital admission for women in Sweden aged 20-45, with follow up from 1994 to 98

\begin{tabular}{|c|c|c|c|c|}
\hline \multirow[b]{2}{*}{ Variable } & \multirow{2}{*}{$\begin{array}{l}\text { Population } \\
\text { (number) }\end{array}$} & \multirow[b]{2}{*}{ Percentage } & \multicolumn{2}{|c|}{$\begin{array}{l}\text { Age adjusted admission rate per } \\
100000 \text { women and year }\end{array}$} \\
\hline & & & Psychiatric & Somatic \\
\hline \multicolumn{5}{|l|}{ Age } \\
\hline $20-24$ & 226218 & 15.6 & & \\
\hline $25-29$ & 304262 & 20.9 & & \\
\hline $30-34$ & 291603 & 20.1 & & \\
\hline $35-39$ & 282384 & 19.4 & & \\
\hline $40-45$ & 384477 & 24.0 & & \\
\hline \multicolumn{5}{|l|}{ Country of birth } \\
\hline Swedish born & 1083173 & & 239 & 3130 \\
\hline Second generation & 176863 & 12.2 & 341 & 3703 \\
\hline Labour, Finnish, southern Europe & 61333 & 4.2 & 395 & 3433 \\
\hline Labour, western/westernised & 30300 & 2.1 & 347 & 3094 \\
\hline Refugee European & 16184 & 1.1 & 340 & 3205 \\
\hline $\begin{array}{l}\text { Refugee non-European } \\
\text { Marital status }\end{array}$ & 85091 & 5.9 & 398 & 3971 \\
\hline \multicolumn{5}{|l|}{ Marital status } \\
\hline Married/cohabiting & 898545 & 61.8 & 206 & 3137 \\
\hline Single & 554399 & 38.2 & 407 & 3417 \\
\hline \multicolumn{5}{|l|}{ Number of children } \\
\hline 0 child & 372614 & 25.6 & 385 & 3019 \\
\hline 1 child & 246807 & 17.0 & 324 & 3490 \\
\hline 2 children & 525264 & 36.2 & 203 & 3245 \\
\hline$>2$ children & 308259 & 21.2 & 282 & 3703 \\
\hline \multicolumn{5}{|l|}{ Disposable income } \\
\hline High & 358204 & 24.7 & 208 & 3045 \\
\hline Middle-high & 363991 & 25.0 & 281 & 3345 \\
\hline Middle-low & 360520 & 24.8 & 295 & 3338 \\
\hline Low & 370229 & 25.5 & 306 & 3262 \\
\hline
\end{tabular}

psychiatric hospital admission than Swedish born women. Women born in western/westernised countries and second generation had nearly as high age adjusted risk ( $\mathrm{HR}=1.44$; $\mathrm{CI}=1.32$ to 1.58 and $\mathrm{HR}=1.42 ; \mathrm{CI}=1.37$ to 1.48 ) of a first psychiatric hospital admission. The risk decreased only slightly when marital status, number of children and disposable income were included in the model. European refugees also showed a similar high risk $(\mathrm{HR}=1.44$; $\mathrm{CI}=1.28$ to 1.62 ), but their risk increased slightly in the main effect model $(\mathrm{HR}=1.55 ; \mathrm{CI}=1.53$ to 1.70$)$.
Single women exhibited the highest risk for a first psychiatric hospital admission, which decreased slightly in the main effect model compared with being married/ cohabitating. Moreover, women without children had a higher risk of a first psychiatric hospital admission than women with children. Women with two children had the lowest risk, which remained unchanged in the main effect model. Women with middle-low and the lowest income had a significantly higher risk for a first psychiatric hospital admission than those with high income. The risk increased in

\begin{tabular}{|c|c|c|}
\hline \multirow[b]{3}{*}{ Variable } & \multicolumn{2}{|l|}{ Model } \\
\hline & \multirow{2}{*}{$\begin{array}{l}\text { Age adjusted } \\
\text { HR (CI) }\end{array}$} & \multirow{2}{*}{$\begin{array}{l}\text { Main effect } \\
\text { HR (CI) }\end{array}$} \\
\hline & & \\
\hline \multicolumn{3}{|l|}{ Country of birth } \\
\hline Swedish born & 1 & 1 \\
\hline Second generation & 1.42 (1.37 to 1.48$)$ & 1.34 (1.29 to 1.40$)$ \\
\hline Labour, Finnish, southern Europe & 1.67 (1.58 to 1.77$)$ & 1.44 (1.36 to 1.53 ) \\
\hline Labour, western/westernised & 1.44 (1.32 to 1.58$)$ & 1.40 (1.27 to 1.53$)$ \\
\hline Refugees, European & $1.44(1.28-1.62)$ & 1.55 (1.37 to 1.75$)$ \\
\hline Refugees, non-European & $1.66(1.58-1.75)$ & 1.61 (1.53 to 1.70$)$ \\
\hline \multicolumn{3}{|l|}{ Marital status } \\
\hline Married/cohabiting & 1 & 1 \\
\hline Single & 1.97 (1.91 to 2.03 ) & 1.88 (1.82 to 1.94$)$ \\
\hline \multicolumn{3}{|l|}{ Number of children } \\
\hline 0 child & 1 & 1 \\
\hline 1 child & $0.89(0.86$ to 0.93$)$ & 0.89 (0.85 to 0.93 ) \\
\hline 2 children & $0.54(0.52$ to 0.56$)$ & $0.61(0.58$ to 0.64$)$ \\
\hline$>2$ children & $0.72(0.69$ to 0.75$)$ & $0.76(0.73$ to 0.80$)$ \\
\hline \multicolumn{3}{|l|}{ Disposable income } \\
\hline High & 1 & 1 \\
\hline Middle-high & 1.34 (1.29 to 1.40$)$ & 1.55 (1.49 to 1.62$)$ \\
\hline Middle-low & $1.42(1.36$ to 1.49$)$ & $1.87(1.78$ to 1.95$)$ \\
\hline Low & $1.47(1.41$ to 1.53$)$ & $1.83(1.75$ to 1.91$)$ \\
\hline
\end{tabular}


the main effect model—-that is, their risk of a first psychiatric hospital admission could not be explained by the explanatory variables.

There was an interaction between country of birth and disposable income that was not included in the main effect model (shown in fig 1). For labour immigrant women, there was a higher incidence rate of first psychiatric hospital admission for women with the lowest income than for those with the highest income. However, the incidence rate for refugees was higher for high income than for low income. The middle-high/middle-low income groups were inconsistent in the pattern for European refugees, partly because of small groups. For Swedish born women, the incidence rate was significantly inverse to the disposable income.

In table 3, the estimated HRs for first somatic hospital admission during 1994-98 are shown in two models: an age adjusted one and a main effect model. In terms of country of birth, only Non-European refugee women had a higher age adjusted risk ( $\mathrm{HR}=1.26 ; \mathrm{CI}=1.24$ to 1.29 ) compared with Swedish born women. This risk did not change when marital status, number of children, and disposable income were included in the model. Labour immigrants from southern Europe, European refugees, and second generation women showed marginally higher age adjusted risks for first somatic hospital admissions than Swedish born women. Women with children had an increased risk of a first somatic hospital admission compared with women without children. This risk remained in the main effect model. In the case of women with low income, the risk for a first somatic hospital admission was slightly increased but disappeared after adjusting for sociodemographic factors.

\section{DISCUSSION}

This study is, as far as we know, the first one to estimate both the first psychiatric hospital admission risk and the first somatic hospital admission risk comparing foreign born and second generation of childbearing age (20-45 years) with Swedish born women.

The main findings of this study are that labour and refugee immigrant women and second generation women had higher age adjusted risks of a first psychiatric hospital admission than Swedish born women. Moreover, the risk decreased only marginally for all foreign born and second generation women, when the sociodemographic factors were taken into consideration. Furthermore, non-European refugee women had a higher age adjusted risk of a first somatic hospital admission than Swedish born women. However, labour immigrants from Finland, southern Europe, western/westernised countries, European refugees and second generation women showed no such increased risk of a first somatic hospital admission compared with Swedish born women.

We found higher risks of first psychiatric hospital admission for all groups of foreign born women in childbearing age than for Swedish born women. These findings are consistent with a recent Swedish study demonstrating increased health services use $^{31}$ and another Swedish study showing an increased risk of hospital admission for psychosis among immigrants, but no generally increased level of psychiatric hospital admissions for immigrants. ${ }^{17}$ The last study was limited to a one year period, and with both men and women from the city in Sweden with the highest proportion of immigrants. Our study shows that all foreign born women, irrespective of being a refugee or labour immigrant, have higher risks of first psychiatric hospital admission than Swedish born women. In general, ethnic minority groups in Sweden confront a cultural barrier, a new language, social devaluation, discrimination, and a lack of social support. ${ }^{26}{ }^{32-34}$ Moreover, resettlement can be seen as either a cultural and psychological life change or a life crisis. ${ }^{35}$ It seems that the foreign born women, regardless of the reason for migration, enter into a process of inwardly and outwardly questioning the new circumstances, whether consciously or unconsciously. ${ }^{36}$ In studies evaluating analytical treatment of immigrants with crises of overload and loss, it was concluded that a quick and superficial adjustment to the new environment without mourning the missed old environment and accepting the different new environment may be marked by prolonged depression. ${ }^{37}$ Furthermore, refugees are often repeatedly exposed to traumatic events and are at risk for post-traumatic stress disorder without seeking professional therapy because of cultural, linguistic, financial, and historical reasons. ${ }^{38}$

The higher risk for a first psychiatric hospital admission among second generation is in agreement with studies,

\begin{tabular}{|c|c|c|}
\hline \multirow[b]{3}{*}{ Variable } & \multicolumn{2}{|l|}{ Model } \\
\hline & \multirow{2}{*}{$\begin{array}{l}\text { Age adjusted } \\
\mathrm{HR}(\mathrm{Cl})\end{array}$} & \multirow{2}{*}{$\begin{array}{l}\text { Main effect } \\
\text { HR (CI) }\end{array}$} \\
\hline & & \\
\hline \multicolumn{3}{|l|}{ Country of birth } \\
\hline Swedish born & 1 & 1 \\
\hline Second generation & 1.07 (1.05 to 1.08$)$ & 1.07 (1.05 to 1.08$)$ \\
\hline Labour, Finnish, southern Europe & 1.11 (1.09 to 1.14 ) & 1.11 (1.08 to 1.13$)$ \\
\hline Labour, western/westernised & $0.99(0.95$ to 1.02$)$ & $0.99(0.96$ to 1.03$)$ \\
\hline Refugees, European & $1.03(0.99$ to 1.10$)$ & $1.05(1.01$ to 1.10$)$ \\
\hline Refugees, non-European & 1.26 (1.24 to 1.29$)$ & $1.26(1.23$ to 1.28$)$ \\
\hline \multicolumn{3}{|l|}{ Marital status } \\
\hline Married/cohabiting & 1 & 1 \\
\hline Single & 1.08 (1.07 to 1.08 ) & 1.15 (1.14 to 1.16$)$ \\
\hline \multicolumn{3}{|l|}{ Number of children } \\
\hline 0 child & 1 & 1 \\
\hline 1 child & 1.23 (1.21 to 1.25 & $1.23(1.21$ to 1.25$)$ \\
\hline 2 children & $1.12(1.11$ to 1.14$)$ & $1.18(1.16$ to 1.20$)$ \\
\hline$>2$ children & $1.24(1.22$ to 1.26$)$ & 1.31 (1.29 to 1.34$)$ \\
\hline \multicolumn{3}{|l|}{ Disposable income } \\
\hline High & 1 & 1 \\
\hline Middle-high & 1.07 (1.05 to 1.08$)$ & 1.04 (1.03 to 1.05$)$ \\
\hline Middle-low & $1.10(1.08$ to 1.11$)$ & 1.06 (1.04 to 1.07$)$ \\
\hline Low & 1.07 (1.06 to 1.09 ) & 1.00 (0.99 to 1.02$)$ \\
\hline
\end{tabular}


which have generally showed that poor health can persist across several generations despite upward intergenerational mobility. ${ }^{22}{ }^{39}$ Significantly lower self esteem, a higher level of parent-child conflict and a higher level of depressive symptoms were found among the second generation adolescent girls. ${ }^{40-42}$

We did not find higher first somatic hospital admission risk for foreign born women than for Swedish born women except the non-European refugees who had an increased risk that persisted when marital status, number of children and income were taken into consideration. However, the women in childbearing age could still show a "healthy migrant effect", which tends to wear off with time..$^{43}{ }^{44}$ Several studies show less use of health care services among immigrants ${ }^{45-47} 13$ and that the access to health services is related to ethnic inequalities. ${ }^{13} 48$

The link between poor socioeconomic conditions, impaired mental and psychological wellbeing, ${ }^{49}$ and depressive symptoms ${ }^{50}$ is well known. Moreover, there are socioeconomic and educational variations in morbidity and in the type of treatment offered to or chosen by the women. ${ }^{5152}$ In this study income does not show any significant differences in risk for the first somatic hospital admission in any of the models. However, several studies suggest that socioeconomic factors are more important for immigrants than nonimmigrants in shaping health status ${ }^{53}$ and that poor foreign born women have significant lower consumption of health services. ${ }^{146}$

This study has limitations, however, some respondents might have left Sweden without reporting it to the Swedish authorities. In that case, they should be regarded as constituting overcoverage. A second disadvantage is the grouping of the foreign born women into labour migrants and refugees including different nationalities, but it was not possible to use more homogeneous groups because of the few cases. In the grouping used some women could also be misclassified, but this should be a minor problem. A third limitation could be the definition of second generation in the Swedish registers-that is, Swedish born individuals with a only one foreign born parent and who may be very similar culturally and socially to Swedish born women with both parents native-born (that is, an underestimation). A fourth limitation is diagnostic misclassification or underclassification, which could be more evident among foreign born women. ${ }^{54-56}$

The strength of this study is that it is based on the "MigMed", a longitudinal research database comprising the entire Swedish population. By using national registration numbers, assigned to each person in Sweden for their lifetime, including refugees and immigrants staying more than six months, it was possible to follow up the first hospital admission, taking in to account country of birth and sociodemographic factors at the start of the study.

In conclusion, more attention needs to be paid to the higher risks of first psychiatric hospital admission for all groups of foreign born women and second generation women in childbearing age. Further studies also need to highlight the reproductive health issues, the lack of knowledge concerning utilisation and accessibility of antenatal and perinatal care and the related morbidity for foreign born women. It is important to increase our knowledge and awareness of the expectations and different needs of dissimilar groups of foreign born and second generation women, as they are a growing group in Swedish society, so as to take account of their distinct health risks and public health needs.

\section{ACKNOWLEDGEMENTS}

We are grateful to Gölin Frank for the statistical support.

\section{Authors' affiliations}

E Robertson, M Malmström, J Sundquist, S-E Johansson, Family Medicine Stockholm, Karolinska Institutet, Stockholm, Sweden

Funding: this study was supported by grants from the Swedish Medical Research Council (K2001-27X-14052-01A) and Axel and Margaret Johnson's Foundation.

Conflicts of interest: none declared.

\section{REFERENCES}

1 Weitzman B, Berry C. Health status and health care utilization among New York City home attendants: an illustration of the needs of working poor, immigrant women. Women Health 1992;19:87-105.

2 Doyal L, ed. Women and health service. Buckingham: Open University Press, 1998.

3 Jacobs D, Tovar J, Hung O, et al. Behavioral risk factor and preventive health care practice survey of immigrants in the emergency department. Acad Emerg Med 2002;9:599-608.

4 Gross R, Brammli-Greenberg S, Remennick L. Self-rated health status and health care utilization among immigrant and non-immigrant Israeli Jewish women. Women Health 2001;34:53-69.

5 Prinsze F. Tuberculosis in countries of the European Union. Infectieziektenbulletin 1997;8:25-7.

6 Huismann A. Migration and health in Germany. In: Huismann A, Weilandt C, Geiger A, eds. Country reports on migration and health in Europe. Bonn: Wissenschaftliches Institut der Ärtze Deutschlands e V, 1997.

7 Gliber M. Migration and health in France. In: Huismann A, Weilandt C, Geiger A, eds. Country reports on migration and health in Europe. Bonn: Wissenschaftliches Institut der Ärtze Deutschlands e V, 1997:106-55.

8 Janson S, Svensson P, Ekblad S. Migration and health in Sweden. In: Huismann A, Weilandt C, Geiger A, eds. Country reports on migration and health in Europe. Bonn: Wissenschaftliches Institut der Ärtze Deutschlands e V, 1997:379-96.

9 Muynck A. Migration and health. In: Huismann A, Weilandt C, Geiger A, eds. Country reports on migration and health in Europe. Bonn: Wissenschaftliches Institut der Ärtze Deutschlands e V, 1997.

10 Carballo M, Divino JJ, Zeric D. Migration and health in the European Union. Trop Med Int Health 1998:3:936-44.

11 Gilthorpe M, Lay-Yee R, Wilson R, et al. Variations in hospitalization rates for asthma among black and minority ethnic communities. Respir Med 1998;92:642-8.

12 Chen K, Tham K, Seow E, et al. Extent and appropriateness of emergency department services usage by foreign workers in Singapore. Ann Acad Med Singapore 1999;28:199-204.

13 Bahl V. Cancer and ethnic minorities - the Department of Health's perspective. Br J Cancer Suppl 1996;29:S2-10.

14 Van Os J, Castle D, Takei N, et al. Psychotic illness in ethnic minorities: clarification from the 1991 census. Psychol Med 1996:26:203-8.

15 Mortensen PB, Cantor-Graae E, McNeil TF. Increased rates of schizophrenia among immigrants: some methodological concerns raised by Danish findings. Psychol Med 1997;27:813-20.

16 Selten JP, Slaets JP, Kahn RS. Schizophrenia in Surinamese and Dutch Antillean immigrants to The Netherlands: evidence of an increased incidence. Psychol Med 1997;27:807-11.

17 Zolkowska K, Cantor-Graae E, McNeil TF. Increased rates of psychosis among immigrants to Sweden: is migration a risk factor for psychosis? Psychol Med 2001;31:669-78.

18 Johansson LM, Sundquist J, Johansson SE, et al. Ethnicity, social factors, illness and suicide: a follow-up study of a random sample of the Swedish population. Acta Psychiatr Scand 1997;95:125-31.

19 Bayard-Burfield L, Sundquist J, Johansson SE. Self-reported long-standing psychiatric illness as a predictor of premature all-cause mortality and violent death: a 14-year follow-up study of native Swedes and foreign-born migrants. Soc Psychiatry Psychiatr Epidemiol 1998;33:491-6.

20 Johansson LM. Migration, mental health and suicide: an epidemiological psychiatric and cross-cultural study. [MD thesis]. Stockholm: Karolinska Institutet, Sweden, 1997.

21 Bayard-Burfield L, Sundquist J, Johansson SE, et al. Attempted suicide among Swedish-born people and foreign-born migrants. Arch Sui Res 1999:5:43-55

22 Harding S, Balarajan R. Limiting long-term illness among black Caribbeans, black Africans, Indians, Pakistanis, Bangladeshis and Chinese born in the UK. Ethn Health 2000;5:41-6.

23 Sundquist J. Ethnicity, social class and health. A population-based study on the influence of social factors on self-reported illness in 223 Latin American refugees, 333 Finnish and 126 south European labour migrants and 841 Swedish controls. Soc Sci Med 1995;40:777-87.

24 Sundquist J, Behmen-Vincevic A, Johansson S-E. Poor quality of life and health in young to middle aged Bosnian female war refugees: a populationbased study. Public Health 1998;112:21-6.

25 Sundquist J, Winkleby MA. Cardiovascular risk factors in Mexican American adults: a transcultural analysis of NHANES III, 1988-1994. Am J Public Health 1999:89.723-30.

26 Kindlund H. Early retirement pension and sickleave among immigrants and Swedes in 1990. [In Swedish]. Stockholm: Swedish National Board of Health and Welfare, 1995:5.

27 Sundquist J, Johansson S-E. Long-term illness among indigenous and foreignborn people in Sweden. Soc Sci Med 1997;44:189-98. 
28 Statistic Sweden. Background information to "Lovise". labour market and education statistics. [In Swedish]. Stockholm: Statistic S'weden, 2002:2.

29 Statistics Sweden. Disposable income. In: Background information to "Louise"; labour market and education statistics. [In Swedish]. Stockholm: Statistics Sweden, 2001:152-8.

30 Kleinbaum D. Survival analysis. New York: Springer Verlag, 1996.

31 Hiern A, Haglund B, Persson G, et al. Is there equity in access to health services for ethnic minorities in Sweden? Eur J Public Health 2001:11:147-52.

32 Sundquist J, Johansson SE. Self-reported poor health and low educational level predictors for mortality: a population-based follow-up study of 39,156 people in Sweden. J Epidemiol Community Health 1997;51:35-40.

33 Sundquist J, Bayard-Burfield L, Johansson LM, et al. Impact of ethnicity, violence and acculturation on displaced migrants: psychological distress and psychosomatic complaints among refugees in Sweden. J Nerv Ment Dis 2000; 188:357-65.

34 Bayard-Burfield L, Sundquist J, Johansson SE. Ethnicity, self reported psychiatric illness, and intake of psychotropic drugs in five ethnic groups in Sweden. J Epidemiol Community Health 2001;55:657-64.

35 Hulewat P. Resettlement: a cultural and psychological crisis. Social Work 1996;41:129-35

36 Kristal-Andersson B. Psychology of the refugee, the immigrant and their children. Development of a conceptual framework and application to psychoterapeutic and related support work. [Monograph]. Lund: University of Lund, Sweden, 2000.

37 Marlin $\mathbf{O}$. Special issues in the analytic treatment of immigrants and refugees. Issues in Psychoanalytic Psychology 1994;16:7-16.

38 Folkes $C$. Thought field therapy and trauma recovery. Int J Emerg Ment Health 2002;4:99-103.

39 Harding S, Balarajan R. Patterns of mortality in second generation Irish living in England and Wales: longitudinal study. BMJ 1996;312:1389-92.

40 Phinney JS. Ethnic identity in adolescents and adults: review of research. Psychol Bull 1990;108:499-514.

41 Fernandez Kelly MP, Schauffer R. Divided fates: immigrant children and the new assimilation. In: Portes $A$, ed. The new second generation. New York: Russel Sage Foundation, 1996:31-3.

42 Rumbaut RC. The crucible within: ethnic identity, self-esteem, and segmented assimilation among children of immigrants. In: Portes A, ed. The new second generation. New York: Russel Sage Foundation, 1996.
43 Lechner IM A. Decrease in the "healthy migrant effect": trends in the morbidity of foreign and German participants in the 1984-1992 Socioeconomic Panel. Gesundheitswesen 1998;60:715-20.

44 Johansson LM, Sundquist J, Johansson SE, et al. Suicide among foreign-born minorities and native Swedes: an epidemiological follow-up study of a defined population. Soc Sci Med 1997;44:181-7.

45 Wen S, Goel V, Williams J. Utilization of health care services by immigrants and other ethnic/cultural groups in Ontario. Ethn Health 1996;1:99-109.

46 Hewitt M, Devesa S, Breen N. Papanicolaou test use among reproductive-age women at high risk for cervical cancer: analyses of the 1995 National Survey of Family Growth. Am J Public Health 2002;92:666-9.

47 Kelaher M. Potts H, Manderson L. Health issues among Filipino women in remote Queensland. Aust J Rural Health 2001;9:150-7.

48 Norredam M, Krasnik A, Petersen J. Access to Danish health care by immigrant women. Access to hospital care among immigrant women with breast cancer compared with Danish women. Ugeskr Laeger $1999 ; 161: 4385-8$

49 Bartley M. Unemployment and ill health: understanding the relationship. J Epidemiol Community Health 1994;48:333-7.

50 Dew MA, Bromet EJ, Penkower L. Mental health effects of job loss in women. Psychol Med 1992;22:751-64.

51 Kuh D, Stirling S. Socioeconomic variation in admission for diseases of female genital system and breast in a national cohort aged 15-43. BMJ 1995:311:840-3

52 Kierulff K, Langenberg P, Guzinski G. The socioeconomic correlates of hysterectomies in the United States. Am J Public Health 1993;83:106-8.

53 Dunn J, Dyck I. Social determinants of health in Canada's immigrant population: results from the National Population Health Survey. Soc Sci Med 2000;51:1573-93.

54 tenHave ML. Inequalities in mental health care and social services utilisation by immigrant women. European Journal of Public Health 1999:9:45-51.

55 Bruxner G, Burvill P, Fazio S, et al. Aspects of psychiatric admissions of migrants to hospitals in Perth, Western Australia. Aust N Z J Psychiatry 1997;31:532-42

56 Li H, Browne A. Defining mental illness and accessing mental health services: perspectives of Asian Canadians. Can J Commun Ment Health 2000; 19: 143-59. 